\section{Elucidations from Pisum sativum to 5-HTT and other genes}

\author{
An Intelligent Person's Guide to Genetics \\ Adrian Woolfson \\ Overlook Press, Wooster Street, New York, USA; 2005. 240pp. \\ $£ 8.99$, paperback. ISBN 0715634232.
}

Heredity (2006) 97, 135. doi:10.1038/sj.hdy.6800855

\section{Reviewed by FK O’Neill}

Genetics is one of those innovations that has grown in the public imagination from fascinating fantasies and potentially troubling 'facts': through Star Trek's Vidiians to concerns regarding GM crops or designer babies.

Many an individual can tell you what they think genetics is, but most would say they would like a better grasp of its development and would appreciate an understanding of the basics. Despite its potentially elitist title (the pun does not work for me), this book makes a good, if particular, introduction to genetics for the curious but uninitiated. The hardback edition gained much valid praise, particularly for Woolfson's crafting of an engaging yet semitechnical read.

If you have missed out on preceding popular books on genetics and genetic history, then this is a timely addition with which to do some catching up. It demonstrates the reach of genetics into our lives, our planet and the way in which genetics has and will reinterpret our existing epistemology. Providing a broad-brush approach to the complexities, this book would be of use to those who need or want to be introduced to the timeline and intricacies of genetics, before they seek more detailed and critical works.

The guide falls roughly into three parts. The first three chapters outline what DNA can and cannot tell us, giving a brief history of how genetics 'evolved' from the works of Darwin, Mendel and William Bateson, and then sketching the interweaving developments of embryology, evolutionary models and early genetic experimentation. The middle chapters give the reader an overview of the technical nitty-gritty of genetics. And the final three chapters bring the reader up to date with a selection of the amazing discoveries and technical feats that have been achieved in the passed 20 or so years, while speculating on the future.

As a passing-the-time read this book is absorbing. Woolfson opens each chapter with a historical allegory, usually from the mid-1800s, often fascinating in itself, but some may find a digression. These accounts are used to reinforce the underlying narrative of genetics being an inheritor of the Enlightenment's enthusiasm for dispelling the 'demon-haunted world' of religion and superstition. Woolfson engages with what he see as the inescapability of human embodiment as an organic machine. His analogies: genetics as the time machine, the engine of evolution or the Boolean logic of the biochemical minicomputer, are appealing.

Each chapter is a neat exposition in a complex field, stuffed with intriguing well-told reports of genetic discoveries. From the recovered works of Mendel and the enmity of Owen for Darwin to the eventual recognition of $\mathrm{McClintock}$ for her jumping genes, to the plethora of information coming from genome maps, these vignettes are set within a popular, if educated, knowledge of the history of science.

Most of the science is accessible. However, there are the odd leaps of knowledge and a basic dictionary of genetics would make a good companion for the less initiated reader who wants to understand more of the technicalities. The book provides ample historic and semipolitical settings, but lacks any significant sociopolitical or ethical critique. Woolfson's preface states that the book 'should not be read as advocating a particular course of action. My view is slightly different: the creation of synthetic life is an inevitability'. The strength of this argument is left unquestioned without the critical edge from perspectives both within and beyond genetics; hence, the reader is left asking 'could and should things have been, or even yet be, otherwise?' Despite these reservations, this is an engaging popular exposition on genetics and would make a good 'book of the week'.

FK O'Neill

ESRC Centre for Economic and Social Aspects of Genetics (CESAGen), IPPP, Lancaster University, Lancaster LA1 4YG, UK

E-mail: f.oneill@lancaster.ac.uk 